\title{
BMJ Open Trends of shoulder instability surgery in Finland: a nationwide register study
}

\author{
Antti Joukainen (D) , ${ }^{1}$ Ville M Mattila, ${ }^{2}$ Vesa Lepola, ${ }^{3}$ Janne Lehtinen, ${ }^{4}$ \\ Juha Kukkonen, ${ }^{5}$ Juha Paloneva ${ }^{6,7}$
}

To cite: Joukainen A, Mattila VM, Lepola V, et al. Trends of shoulder instability surgery in Finland: a nationwide register study. BMJ Open 2020;10:e040510. doi:10.1136/ bmjopen-2020-040510

- Prepublication history for this paper is available online. To view these files, please visit the journal online (http://dx.doi. org/10.1136/bmjopen-2020040510).

Received 14 May 2020 Revised 30 July 2020 Accepted 11 September 2020

Check for updates

(c) Author(s) (or their employer(s)) 2020. Re-use permitted under CC BY-NC. No commercial re-use. See rights and permissions. Published by BMJ.

${ }^{1}$ Department of Orthopaedics, Traumatology and Hand Surgery, Kuopio University Hospital, Kuopio, Finland

${ }^{2}$ Department of Orthopaedics and Traumatology, Tampere

University Hospital, Tampere,

Finland

${ }^{3}$ Pohjola Hospital Tampere, Tampere, Finland

${ }^{4}$ Hatanpää Unit, Tampere University Hospital, Tampere, Finland

${ }^{5}$ Department of Orthopaedics and Traumatology, Turku University Hospital, Turku, Finland

${ }^{6}$ Department of Surgery, Central Finland Hospital Nova, Jyvaskyla, Finland

${ }^{7}$ University of Eastern Finland, Kuopio, Finland

Correspondence to

Dr Antti Joukainen;

antti.joukainen@kuh.fi

\section{ABSTRACT}

Objective Rate of shoulder instability surgery (SIS) has increased in different specific populations. We analysed nationwide trend of SIS in adults in Finland between 1997 and 2014.

Design A retrospective register study.

Setting National Hospital Discharge Register of Finland. Participants A total of 22550 adult patients with SIS in Finland (1997-2014).

Primary and secondary outcome measures Analysis included appropriate diagnosis (International Classification of Diseases 10) and procedure coding combinations applicable for SIS. The primary outcome variable was the incidence of SIS per 100000 person-years, and the secondary outcomes were the study year, sex, age groups (18-29, 30-49 and over 50 years of age) and the type of hospital (public or private).

Results The overall nationwide rate of SIS in adults increased 177\% between 1997 and 2014 in Finland. The rate was the lowest (13/100 000 person-years) in 1997, and the peak rate (40/100 000 person-years) was noted in 2007. The increase in rate was rapid between 1997 and 2007, after which the rate became stable. During the study period, the highest increases were noted in the young adults age group $(270 \%)$, and especially in the middle-aged group who were operated on in private hospitals $(930 \%)$.

Conclusions The rate of SIS increased almost threefold in Finland from 1997 to 2014. The increase was most significant in young and middle-aged adults (18-50 years), in men, and in private hospitals.

\section{INTRODUCTION}

The glenohumeral joint is vulnerable to dislocations and chronic instability. The overall incidence rate of shoulder dislocation was found to be 56/100 000 person-years in a Norwegian study. ${ }^{1}$ An unstable or painful shoulder with a pathologic instability lesion in glenohumeral joint is an indication for shoulder instability surgery (SIS), and the incidence of these operations has been growing in selected cohorts. ${ }^{2-5}$ However, there are still no unambiguous indications for surgical treatment, and the results of conservative treatment are often good. ${ }^{6}$ Most patients undergoing shoulder stabilisation surgery are around 20 years old male patients. ${ }^{15}$ The increase in shoulder surgery incidences has also been noticed elsewhere. Rotator cuff procedure incidence increased by 204\% between 1998

\section{Strengths and limitations of this study}

- The study makes use of Finnish nationwide discharge register data to provide a large population in which to study trends of shoulder instability surgery (SIS).

- The coverage and accuracy of the register data are good.

- The 17-year study period provides a long perspective on the trends of SIS over time, and for comparing the numbers in other populations.

- The diversity of the diagnosis and operative procedure coding classifications concerning shoulder instability is a limitation of the study.

and 2011 in Finland. ${ }^{7}$ A cohort study showed that the incidence of SIS in Norway was 12/100 000 person-years in 2009, and that there was a 37\% increase in SIS in Sweden between 2006 and 2008. ${ }^{38}$ However, at present, no literature on the long-term progress of the SIS incidences on a nationwide level exists. A long-term analysis of incidence of SIS on a nationwide level enables evaluation of progression of SIS in general. It also constitutes a baseline for comparing the incidences in other countries. The present study investigated nationwide incidence of SIS in Finland over a 17-year time period.

\section{METHODS}

We conducted a nationwide hospital discharge register-based study in Finland to assess whether the incidence of SIS had changed between January 1997 and December 2014. We hypothesised that the overall incidence of SIS would show an increase in total number and number of subgroups.

We reviewed the nationwide data from the Finnish National Hospital Discharge Register (NHDR) for the period 1 January 1997 through 31 December 2014 to evaluate the incidence of SIS. Inpatient and outpatient data collection for the Finnish NHDR is mandatory for all public and private hospitals. The NHDR contains comprehensive information on diagnoses and operations performed in Finland. 
Table 1 ICD-10 diagnosis codes related to shoulder instability procedures in Finland 1997-2014. The procedure codes were NBE20-45, NBE99, NBG01 or NBK93, according to the Finnish version of NOMESCO

Numbers of a combination of diagnosis and procedure related to shoulder instability

ICD-10 diagnosis coding related to shoulder instability procedures procedures in Finland 19972014, n (\%)

$\begin{array}{lr}\text { M24.2 Disorder of ligament } & 1887(8.4) \\ \begin{array}{l}\text { M24.3 Pathological dislocation } \\ \text { and subluxation of joint (not } \\ \text { elsewhere classified) }\end{array} & 77(0.3)\end{array}$

\begin{tabular}{ll}
$\begin{array}{l}\text { M24.4 Recurrent dislocation and } \\
\text { subluxation of joint }\end{array}$ & $5447(24.2)$ \\
\hline M25.2 Unstable joint & $2118(9.4)$ \\
$\begin{array}{l}\text { S43.0 Dislocation of shoulder } \\
\text { joint }\end{array}$ & $9352(41.5)$ \\
$\begin{array}{l}\text { S43.3 Dislocation of other and } \\
\text { unspecified parts of shoulder }\end{array}$ & $351(1.6)$ \\
\end{tabular}
girdle

$\begin{aligned} & \text { S43.4 Sprain and strain of } \\ & \text { shoulder joint }\end{aligned}$
$\begin{aligned} & \text { S43.7 Sprain and strain of } \\ & \text { other and unspecified parts of } \\ & \text { shoulder girdle }\end{aligned}$
$\begin{aligned} & \text { All shoulder instability } \\ & \text { procedures related to instability } \\ & \text { diagnoses from } 1997 \text { to } 2014 \text { in }\end{aligned}$
Finland

ICD-10, International Classification of Diseases 10; NOMESCO, Nordic Medico-Statistical Committee.

All Finns aged 18 years or older were included in the study. Data for the study were collected from the Finnish NHDR using appropriate International Classification of Diseases 10 (ICD-10) diagnosis ${ }^{9}$ (table 1) and procedure coding combinations applicable for SIS. The Nordic Medico-Statistical Committee (NOMESCO) classification of surgical procedures (Finnish version) codes are used in the Finnish NHDR. The codes for SIS included in the study were shoulder glenohumeral capsule or ligament-related reconstructions (NBE20-45, NBE99) and other reconstructions (NBG01, NBK93) for glenohumeral instability. Acromio-clavicular and sterno-clavicular reconstructions (NBE70, NBE72) were not included in data collection. It was not possible to collect from the register data the side of the operated shoulder, or data of primary or revision procedure.

The primary outcome variable was the incidence of SIS per 100000 person-years that was analysed with stratification by study year, age groups (18-29, 30-49 and more than 50 years of age) and the type of the hospital (public or private).

Incidence rates were calculated using the annual adult population size (ranging from 4 million to 4.4 million during the study period) obtained from Statistics Finland, a statutory electronic national population register. ${ }^{10}$ The incidence was based on the size of the entire population $\geq 18$ years old in Finland rather than on cohort-based estimates. Accordingly,

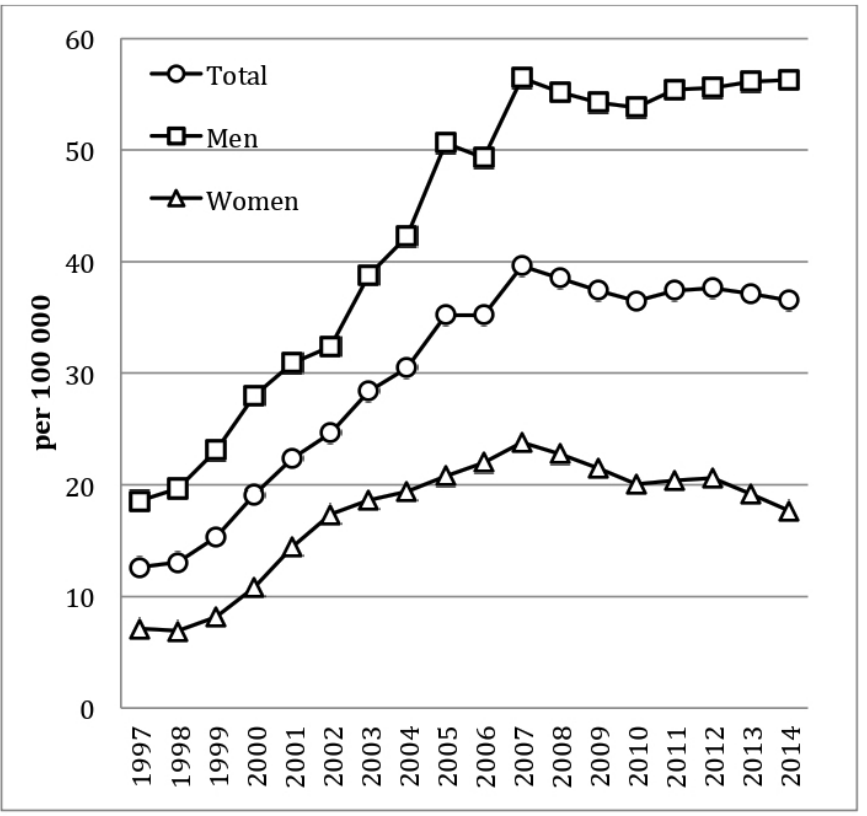

Figure 1 Incidence of shoulder instability surgery in Finnish men and women aged 18 or more from 1997 to 2014. Incidence numbers include patients who have a combination of ICD-10 diagnosis of shoulder instability and operative codes related to shoulder stabilising surgery (NBE20-45, NBE99, NBG01 and NBK93). ICD-10, International Classification of Diseases 10.

CIs were not calculated. Statistical analyses were performed using SPSS V.22.0 software.

We used the Strengthening the Reporting of Observational Studies in Epidemiology cohort checklist when writing our report. ${ }^{11}$

\section{Patient involvement}

No patients were involved in the development of the research question, the outcome measures, the design or the implementation of the study. There are no plans to disseminate the results of the research directly to study participants.

\section{RESULTS}

The results of the study are presented in figures 1-4. The total number of SIS carried out between 1997 and 2014 was 22893 (table 1). Of these, 98\% were shoulder capsulerelated procedures (codes NBE20-45, NBE99) and 2\% other shoulder stabilising procedures (codes NBG01, NBK93). The diagnosis codes used did not change during the study period. The four most common diagnosis codes were used in $87.4 \%$ of the procedures (table 1). The mean age of the patients was 35 (SD 12) years. The mean age of men increased slightly from 31 years (SD 12) to 33 years (SD 11) years during the study period. The mean age of women remained unchanged (38 years (SD 14) in 1997 and 37 years (SD 13) in 2014).

The incidence of SIS was 13/100 000 person-years at the beginning of the study period in 1997, and it increased by $208 \%$ to a peak value of $40 / 100000$ person-years in 2007. After 2007 , the incidence decreased slightly and then remained at a stable level of 37 procedures/100 000 person-years. Overall, 


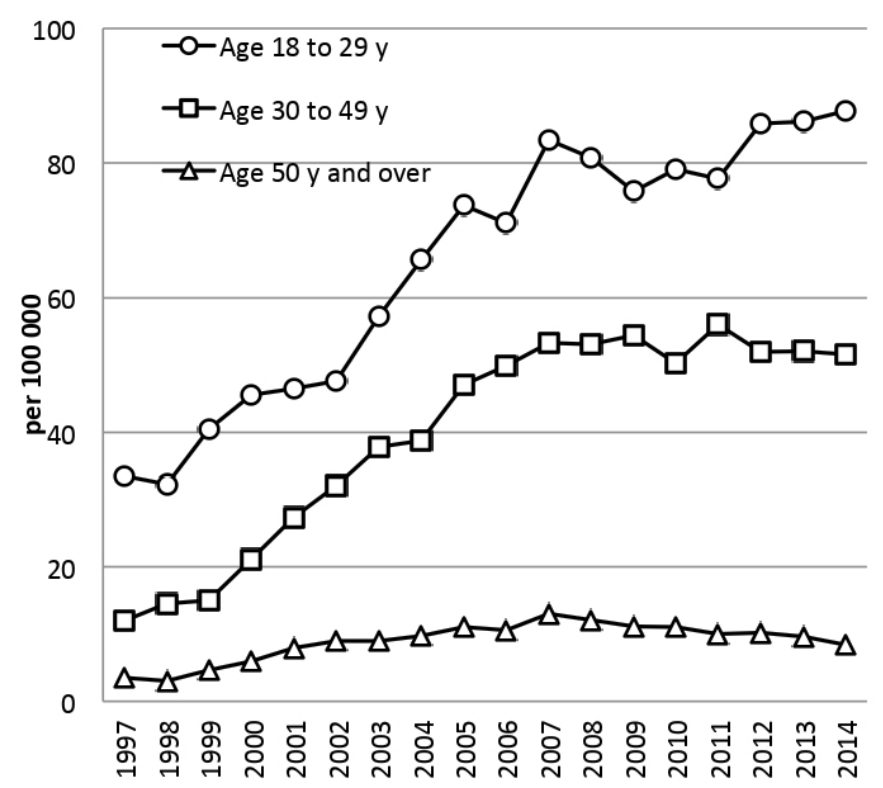

Figure 2 Incidence of shoulder instability surgery by age in Finland from 1997 to 2014.

the incidence of SIS increased 177\% during the whole study period from 1997 to 2014. The incidence in men increased from 19 to 56 operations/100 000 person-years between 1997 and 2007 and thereafter remained at the same level. In women, the incidence increased from 7 to approximately 24/100 000 person-years between 1997 and 2007 (figure 1). The incidence of shoulder stabilising surgery in men compared with women was 2.6-fold in 1997 and 3.2-fold in 2014.

Most of the SIS were done in persons aged 18-29 years. The incidence increased in this group by $270 \%$ during the study period of 1997-2014, and the peak incidence was calculated to be $89 / 100000$ person-years at the end of the study period. In persons aged between 30 and 49, high proportional rise (440\%) was observed from 1997 to 2007, after which the

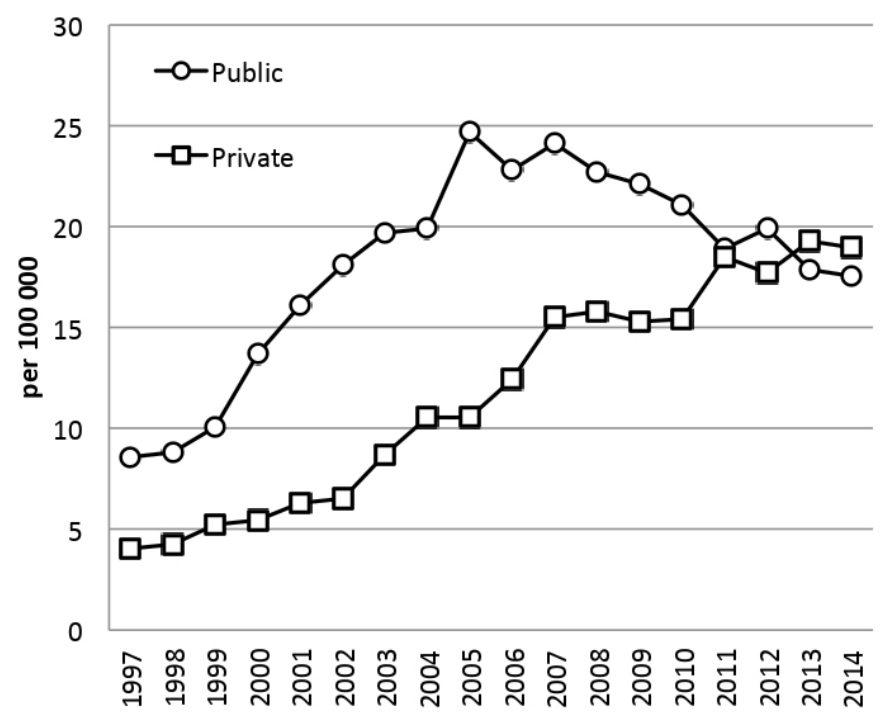

Figure 3 Incidence of shoulder instability surgery in public and private hospitals in Finland from 1997 to 2014.

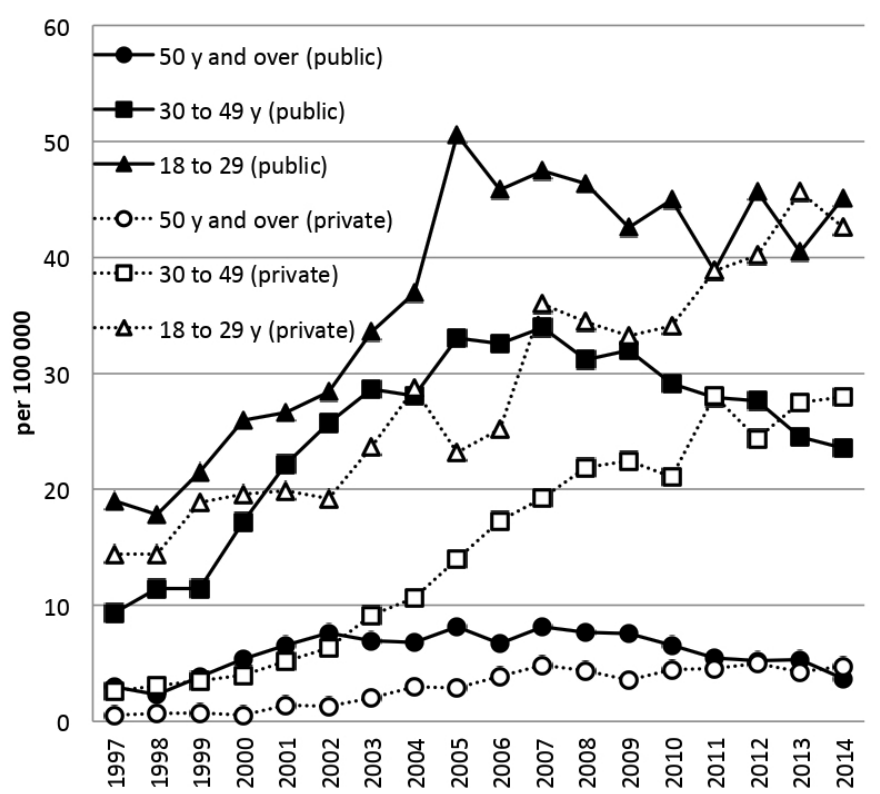

Figure 4 Incidence of shoulder instability surgery from 1997 to 2014 in Finland by patient age and type of hospital.

incidence remained at the level of 50/100 000 person-years. The oldest age group (more than 50 years of age) underwent fewer shoulder stabilising procedures, reaching the peak incidence of 12/100 000 person-years in 2007 (figure 2).

The proportion of operations carried out in public and private hospitals is presented in figure 3 . In the beginning of the study period, the incidence of SIS was more than twice as high in public hospitals compared with private hospitals. During the study period, however, the incidence of SIS increased steadily in private hospitals. This increase resulted in a slightly higher incidence of SIS in the private sector at the end the study period (figure 3). Incidence figures for instability surgery by age group and type of hospital are presented in figure 4. During the whole study period, the highest proportional rise $(930 \%)$ was seen in the middleaged (30-49 years) group in private hospitals. The young adults age group (18-29) was the most common patient group in both public and private hospitals, with an incidence of more than 40/100 000 person-years at the end of the study period.

\section{DISCUSSION}

The main finding of our present study was that the overall nationwide incidence of SIS in Finland increased by 177\% between 1997 and 2014. Between 1997 and 2007, the increase was $208 \%$ and reached a peak value of 40/100 000 personyears in 2007 . After 2007 , the incidence declined slightly to the level of 37/100 000 person-years. The increase in stabilising surgery was the most notable in the group of young adults (18-29) who were treated in private hospitals. The incidence of SIS showed a steady increase in private hospitals during the whole study period, but a decrease in public hospitals after 2005. 


\section{Comparison with the existing literature}

A previous study of shoulder capsular surgery in Finland presented 90\% increase in procedures during 1999-2007. ${ }^{12}$ The period analysed in the recent study is shorter than in our material, and the study shows incidences lower than in our results, probably because of differing inclusion of ICD-10 and procedural codings in the data retrieval. We have included in our retrieval also other than shoulder capsule procedures for shoulder instability, which have produced slightly higher incidence numbers. For example, in 2007, the total incidence of shoulder capsular surgery was 33/100 000 person-years, and the rate of SIS 40/100 000 person-years in our material. However, the trends are parallel during the analysed time period in the recent and in our study, and support the finding of the increasing incidence of SIS.

A recent Norwegian cohort study presented additional information of the overall incidence of SIS 12/100 000 person-years in 2009. ${ }^{3}$ Thus, the incidence of SIS in Norway seems to be $32 \%$ of the incidence in Finland in the same year. Another governmental institute report from Sweden reports a corresponding incidence of SIS in Sweden as in Norway. ${ }^{8}$ The reason for the threefold incidence of SIS in Finland compared with Norway and Sweden is unknown and is a subject for future investigation. The incidence of SIS in the Norwegian study is based on the national Norwegian Patient Register numbers and NOMESCO codings, but no specific codes included in the study material are not given in the paper, which may have resulted a lower incidence of SIS. In our material, the four most common diagnosis codes comprised $87.4 \%$ of the all SIS codes, and there were no observable changes in codes used in the study period. Our results only cover citizens over the age of 18 , and this may partially explain the differences because the incidence of shoulder instability is less in age groups younger than 14 years of age. ${ }^{13}$ One possible explanation for the increase in SIS in Finland may be the advancements of shoulder arthroscopy techniques, a phenomenon also described in other studies during the last 20 years. ${ }^{14} 15$

A noteworthy increase in instability procedures in Finland was seen in the age group of young adults. This is a plausible consequence of the fact that young adults have the highest risk of primary shoulder dislocation and instability. ${ }^{1516}$ The high occurrence of shoulder instability among young adults, and especially among men, has been described in several studies. ${ }^{4} 17-19$

The incidence of SIS among the middle-aged group showed a decrease in public hospitals after 2007, but a steadily rising trend in private hospitals. The cause of this phenomenon is obviously multifactorial. The characteristics of the patients and the indications for surgery may differ in public and private hospitals. ${ }^{1420}$ Economic intensives may favour doing surgeries in private sector, where salaries are based on the fee-for-service model, whereas fixed monthly salary model is mainly used in public sector in Finland. ${ }^{21} 22$

It is possible to compare the results of this study with the incidences of other types of shoulder surgery in Finland. The incidence of rotator cuff repair (RCR) increased between 1998 and 2011 in Finland by 204\%. In 2011, the incidence of RCR was 131/100 000 person-years, which is 3.5-fold compared with the incidence of SIS during the same year. The increase in RCRs continued after 2005 in private healthcare only, and a corresponding trend has also been found in the SIS data, although 2years later than in RCR incidence. ${ }^{7}$

The national incidences of subacromial decompression (SAD) have also been reported from Finland. The incidence has declined since 2007, when a peak value of SAD of 163/100 000 person-years was reached. ${ }^{23}$ The latest published incidence of SAD was 131/100 000 person-years in 2011, which is 3.5-fold compared with SIS in the same year.

\section{Strengths and weaknesses}

The strength of the study is the population-based nationwide data with good coverage and accuracy. ${ }^{24-26}$ Another strength of the study is the long (17 years) period that was analysed. This gives a valuable perspective on the trends of SIS over time, and will be informative for the planning of healthcare, and for comparing the numbers in other populations.

A limitation of the study is the diversity of the diagnosis and operative procedure coding classifications concerning shoulder instability. It is not possible to identify the revision procedures from the material due to lacking laterality data of the procedure. In addition, the ICD-10 diagnosis or NOMESCO procedural coding classifications do not include unambiguous guidance on how to use the codes for different conditions or procedures.

\section{Implications for health, social services and future research}

The increasing number and incidence of SIS in Finland may be considered as a sign of the advances in surgical treatment for shoulder instability. It is unlikely that the incidence of absolute shoulder instability has increased nationwide during the study period. It is possible that the better availability of surgical treatment has increased surgery rates. This can be seen as a more efficient healthcare service, but also as an economic burden. The possible achieved health value of treatment remains obscure, and will remain so until patientreported outcome measurements (PROMs) are registered and analysed. Therefore, we were unable to analyse from our data the value, that is, health outcomes per treatment costs, of SIS in Finland. ${ }^{21}$

Public healthcare in Finland is provided by the community, and as such is accessible by all citizens at a reasonable cost. Consumers are also free to use private healthcare, where the costs are covered by insurance companies, employers or by the patients themselves. The payment system for the practitioners is 'fee-for-service'. 2122 The difference in incentives and the beliefs of physicians about the indications for surgery between public and private healthcare and also several other factors may have an effect on the differing SIS incidences. ${ }^{20}$

\section{CONCLUSIONS}

In conclusion, the incidence of SIS in Finland increased by $177 \%$ during the 17 -year study period. The incidence reached a peak value of 40/100 000 person-years in 2007, and was $37 / 100000$ person-years at the end of the study period in 
2014. The increase of SIS was the most notable among young and middle-aged adults, in men, and in private hospitals.

Taking into account the limitations of the Finnish NHDR register data and its analysis in this study, we recommend that a consensus agreement of diagnostic and surgical procedure coding in the most common pathologic conditions in shoulder instabilities be created. It would be in the interests of all stakeholders to have a common, reproducible and unequivocal classification system of shoulder instability conditions. We also recommend the systematic easy-to-access registering of PROMs for the NHDR or other applicable national patient register. These advancements would produce more reliable data on the shoulder surgery procedures in future, and thus create possibilities to analyse the results and value of the treatment of different shoulder instability conditions.

Acknowledgements We are grateful to Mr Peter Heath for English language revision of the manuscript.

Contributors AJ contributed to study design, data analysis and interpretation, and writing of the manuscript. VM contributed to study design, data acquisition and interpretation, and critical revision of the manuscript. VL, JL and JK contributed to data interpretation and critical revision of the manuscript. JP contributed to study design, data acquisition and analysis, interpretation, and critical revision of the manuscript. All authors read and approved the final manuscript.

Funding The authors have not declared a specific grant for this research from any funding agency in the public, commercial or not-for-profit sectors.

Competing interests None declared.

Patient consent for publication Not required.

Ethics approval Ethical approval was granted by the Finnish National Institute for Health and Welfare (Dnr THL/89/5.05.00/2012, dated 18 January 2012).

Provenance and peer review Not commissioned; externally peer reviewed.

Data availability statement The datasets generated and/or analysed during the current study are available from the corresponding author on reasonable request.

Open access This is an open access article distributed in accordance with the Creative Commons Attribution Non Commercial (CC BY-NC 4.0) license, which permits others to distribute, remix, adapt, build upon this work non-commercially, and license their derivative works on different terms, provided the original work is properly cited, appropriate credit is given, any changes made indicated, and the use is non-commercial. See: http://creativecommons.org/licenses/by-nc/4.0/.

ORCID iD

Antti Joukainen http://orcid.org/0000-0002-1428-5700

\section{REFERENCES}

1 Liavaag S, Svenningsen S, Reikerås O, et al. The epidemiology of shoulder dislocations in Oslo. Scand J Med Sci Sports 2011;21:e334-40.

2 Ablove $\mathrm{RH}$, Aul A, Baer G. The incidence and demographics of shoulder repair in Wisconsin, 2002-2010. WMJ 2014;113:223-6.

3 Blomquist J, Solheim E, Liavaag S, et al. Shoulder instability surgery in Norway: the first report from a multicenter register, with 1-year follow-up. Acta Orthop 2012;83:165-70.
4 Zhang AL, Kreulen C, Ngo SS, et al. Demographic trends in arthroscopic slap repair in the United States. Am J Sports Med 2012;40:1144-7.

5 Kraeutler MJ, McCarty EC, Belk JW, et al. Descriptive epidemiology of the MOON shoulder instability cohort. Am J Sports Med 2018;46:1064-9.

6 Rees JL, Shah A, Edwards K, et al. Treatment of first-time traumatic anterior shoulder dislocation: the UK TASH-D cohort study. Health Technol Assess 2019;23:1-104.

7 Paloneva J, Lepola V, Äärimaa V, et al. Increasing incidence of rotator cuff repairs--A nationwide registry study in Finland. BMC Musculoskelet Disord 2015;16:189.

8 Socialstyrelsen. Socialstyrelsen statistical databases. Available: http://www.socialstyrelsen.se/english [Accessed 20 Dec 2016].

9 ICD. International statistical classification of diseases and related health problems 10th revision. version, 2016. Available: http://apps. who.int/classifications/icd10/browse/2016/en [Accessed 15 Dec 2016].

10 Statistics Finland. Population structure. Available: http://www.stat.fi/ til/vaerak/ [Accessed 7 Nov 2016].

11 von Elm E, Altman DG, Egger M, et al. The strengthening the reporting of observational studies in epidemiology (STROBE) statement: guidelines for reporting observational studies. Epidemiology

12 Kavaja L, Malmivaara A, Lähdeoja T, et al. Shoulder capsular surgery in Finland between 1999 and 2008: a nationwide register analysis. Scand J Surg 2018;107:172-9.

13 Leroux T, Ogilvie-Harris D, Veillette C, et al. The epidemiology of primary anterior shoulder dislocations in patients aged 10 to 16 years. Am J Sports Med 2015;43:2111-7.

14 Berendes TD, Pilot P, Nagels J, et al. Survey on the management of acute first-time anterior shoulder dislocation amongst Dutch public hospitals. Arch Orthop Trauma Surg 2015;135:447-54.

15 Owens BD, Tokish J. Recurrent anterior shoulder instability. Orthopedics 2012;35:496-7.

16 Eljabu W, Klinger HM, von Knoch M. The natural course of shoulder instability and treatment trends: a systematic review. J Orthop Traumatol 2017;18:1-8.

17 Amako M, Sasao H, Matsuhashi Y, et al. Incidence and characteristics of traumatic shoulder instability in Japanese military cadets. Mil Med 2016;181:577-81.

18 Olds M, Ellis R, Donaldson K, et al. Risk factors which predispose first-time traumatic anterior shoulder dislocations to recurrent instability in adults: a systematic review and meta-analysis. $\mathrm{Br} \mathrm{J}$ Sports Med 2015;49:913-22.

19 Zacchilli MA, Owens BD. Epidemiology of shoulder dislocations presenting to emergency departments in the United States. J Bone Joint Surg Am 2010;92:542-9.

20 Birkmeyer JD, Reames BN, McCulloch P, et al. Understanding of regional variation in the use of surgery. Lancet 2013;382:1121-9.

21 Wei DH, Hawker GA, Jevsevar DS, et al. Improving value in musculoskeletal care delivery: AOA critical issues. J Bone Joint Surg Am 2015;97:769-74.

22 Lansky D, Nwachukwu BU, Bozic KJ. Using financial incentives to improve value in orthopaedics. Clin Orthop Relat Res 2012;470:1027-37.

23 Paloneva J, Lepola V, Karppinen J, et al. Declining incidence of acromioplasty in Finland. Acta Orthop 2015;86:220-4.

24 Huttunen TT, Kannus P, Pihlajamäki H, et al. Pertrochanteric fracture of the femur in the Finnish national hospital discharge register: validity of procedural coding, external cause for injury and diagnosis. BMC Musculoskelet Disord 2014;15:98

25 Mattila VM, Sillanpää P, livonen T, et al. Coverage and accuracy of diagnosis of cruciate ligament injury in the Finnish national hospital discharge register. Injury 2008;39:1373-6.

26 Sund R. Quality of the Finnish hospital discharge register: a systematic review. Scand J Public Health 2012;40:505-15. 